\title{
atherosclerosis
}

ELSEVIER

Atherosclerosis $121(1996) 185-191$

\section{Association of plasma fibrinogen levels with coronary artery disease, smoking and inflammatory markers}

\author{
Moniek P.M. de Maat ${ }^{\mathrm{a}, \mathrm{b}}$, Anneke Pietersma ${ }^{\mathrm{c}}$, Marcel Kofflard ${ }^{\mathrm{d}}$, Wim Sluiter ${ }^{\mathrm{c}}$, \\ Cornelis Kluft ${ }^{\text {b }}$ \\ ${ }^{a}$ Department of Internal Medicine II, Erasmus University, Rotterdam, The Netherlands \\ ${ }^{\mathrm{b}}$ Gaubius Lahoratory TNO-PG, P.O. Box 2215, 2301 CE Leiden, The Netherlands \\ 'Department of Biochemistry, Erasmus University, Rotterdam, The Netherlands \\ ${ }^{a}$ Department of Cardiology, Erasmus University, Rotterdam, The Netherlands
}

Received 27 April 1995; revision received 4 September 1995; accepted 12 September 1994

\begin{abstract}
The plasma level of fibrinogen is associated with the risk of ischaemic heart disease (IHD) and the severity of atherosclerosis. It has been suggested that an increased plasma level of fibrinogen is a coronary risk indicator because it reflects the inflammatory condition of the vascular wall. An inflamed vascular wall may increase the production of the cytokines interleukin 6 (IL6), interleukin $1 \beta$ (IL1 $\beta$ ), and tumour necrosis factor $\alpha$ (TNF $\alpha$ ), which have a major role in the regulation of synthesis in the liver of acute phase proteins, including fibrinogen. Smoking has also been reported to increase the levels of fibrinogen and C-reactive protein (CRP). This may indicate that smoking induces an inflammatory reaction, probably of the pulmonary bronchi and alveolae. Therefore, we anticipated that with both types of inflammation the levels of acute phase proteins and cytokines would be related. We have investigated the contribution of inflammation to the plasma levels of fibrinogen in 34 patients with severe coronary artery disease (CAD) and 30 healthy controls comparable for age and smoking habits. We did not find a parallel in the effects of smoking and ischaemic heart disease on the plasma levels of fibrinogen, CRP, IL6, IL1 $\beta$ and TNF $\alpha$. Cardiovascular disease had its most important effect on the plasma fibrinogen level, while smoking appeared to increase the CRP levels, while both CAD and smoking seemed to affect the IL6 levels. Our results indicate that both smoking and CAD induce an inflammatory condition but that the increase of plasma levels of different inflammatory markers is complex. Although the acute phase reaction is the main regulatory mechanism of fibrinogen, the increase of fibrinogen in our group of CAD patients could not be fully explained by increased inflammation.
\end{abstract}

Keywords: Fibrinogen; C-reactive protein; Acute phase; Coronary artery disease; PTCA

\footnotetext{
* Corresponding author, at the Leiden address. Tel.: +3171 1818.18; Fax: + 3171 181904; e-mail m.demaat@pg.tno.n1. 


\section{Introduction}

An elevated plasma fibrinogen level has been identified as an independent risk indicator for ischaemic heart disease and the severity of atherosclerosis in healthy populations [1-3]. Although several possible mechanisms have been postulated [4-6], the underlying mechanism has not yet been elucidated. One of the hypotheses is that increased plasma fibrinogen level may be a risk indicator because the level of fibrinogen, an acute phase protein, reflects the inflammatory state of the vascular wall. This is based on the theory of Ross et al. [7] that advanced lesions of atherosclerosis result from an excessive inflammatory-fibroproliferative response to numerous different forms of insults. The resulting low grade inflammation of the vascular wall has even been suggested to be the main 'mechanism' of atherosclerosis [7].

The role of inflammation in cardiovascular disease is further supported by reports on associations of the pathogenesis of coronary artery disease and leucocyte count $[8,9]$, monocyte count [10], cytokines in the atheroma [11], expression of granulocyte and monocyte receptors [12], and inflammatory infiltrates in the cardiac arteries [13].

An inflamed vascular wall in patients with coronary artery disease may increase the levels of the cytokines IL6, ILl $\beta$ and TNF $\alpha$. This is relevant, because these cytokines regulate the synthesis of acute phase proteins in the liver [14]. Therefore, we may expect that not only the plasma levels of fibrinogen, but also those of other markers of inflammatory response, such as levels of the sensitive acute phase protein CRP and those of IL6, IL $1 \beta$ and TNF $\alpha$, will increase.

Smoking increases the plasma levels of both fibrinogen [15-17] and CRP [18,19] in healthy individuals, which suggests that smoking induces an inflammatory reaction. This is probably a low grade inflammation of the pulmonary bronchi and alveolae [20], which may result in a general acute phase reaction with increased fibrinogen and CRP levels. It has even been suggested that smoking is a cardiovascular risk factor through its elevating effect on the plasma fibrinogen level [2].
There are indications that the effect of smoking on the plasma fibrinogen level is greater in healthy volunteers than in patients who already have an increased plasma fibrinogen level. In healthy male volunteers a mean increase of $12 \%$ has been reported [15,17,21-24], while in vascular disease patients the plasma fibrinogen levels were comparable in the non-smoking and the smoking patients [25] or only slightly higher in the smokers $(6 \%, P<0.0001)[26]$.

In this study we established the effects of inflammation on the fibrinogen increase induced by coronary artery disease and by smoking.

\section{Patients and methods}

\subsection{Patients and controls}

Thirty-four patients ( 26 male, 8 female) with angina complaints and scheduled for percutaneous coronary transluminal angioplasty (PTCA) were enrolled in this study. A detailed description of the characteristics of the patient group is given in [27]. Briefly: on the diagnostic coronary angiogram only one target vessel was considered responsible for the complaints. The mean (1 S.D.) age was $54.2(8.3)$ years. Fifteen patients had a history of myocardial infarction, 6 patients had undergone PTCA earlier and in 2 patients a coronary artery bypass graft (CABG) operation had been performed before their participation in the study. The severity of anginal complaints was scored according to the New York Heart Association classification: eight patients were in Class II, 17 patients were in Class III and 9 patients were in Class IV. The patients did not take any medication known to influence fibrinogen levels.

On coronary angiography, one vessel disease (VD) was documented in 29 patients, two VD in 4 patients and three VD in 1 patient. The target vessel was the left descending artery (LAD) in 17 patients, the left circumflex artery in 7 patients and the right coronary artery in 10 patients.

Since the levels of inflammatory markers are associated with age [28] and smoking habits, a control group was composed with comparable age and smoking habits. Fifteen non-smoking and 15 
smoking healthy male blood donors, older than 45 years, who consecutively visited the Rotterdam Red Cross Bloodbank were included in the control group.

The study was conducted in accordance with the Helsinki Declaration: approval was given by the Medical Ethical Committee of the Erasmus University, Rotterdam and written consent was obtained from the patients.

\subsection{Smoking}

If smoking was stopped within 1 month before blood sampling the participant was considered a smoker. The ex-smokers who had stopped smoking at least 6 months before blood sampling were considered non-smokers. No patients had stopped smoking between 1 and 6 months before the start of the study. Sixteen patients and 15 controls were smokers.

\subsection{Blood sampling}

Blood was collected and anticoagulated with $5.4 \mathrm{mM}$ EDTA on melting ice. After centrifugation at $2000 \times g$ for $15 \mathrm{~min}$, the plasma was collected and stored at $-80^{\circ} \mathrm{C}$ until use.

\subsection{Fibrinogen}

Fibrinogen is measured with an enzyme immuno assay that uses the monoclonal antibody G8 (directed against the COOH-terminal part of the fibrinogen $\alpha$-chain) as a catching antibody and peroxidase conjugated Y18 (directed against the $\mathrm{NH}_{2}$-terminal part of the fibrinogen $\alpha$-chain) as tagging antibody [29].

\subsection{C-reactive protein}

C-reactive protein is measured with a sensitive enzyme immuno assay that uses rabbit antihuman C-reactive protein (Dako A/S, Glostrup, Denmark) as a catching and a tagging antibody.

\subsection{Cytokines}

IL6, IL1 $\beta$ and TNF $\alpha$ were measured with en- zyme immuno assays according to the instructions of the manufacturer (Mcdgenix, Amersfoort, the Netherlands). The lower detection limit of the IL6 and ILl $\beta$ assays was 3 $\mathrm{pg} / \mathrm{ml}$.

\subsection{Statistical analysis}

The distribution of the variables under study was positively skewed. Logarithmic transformation gave a normal distribution for fibrinogen, CRP and TNF $\alpha$, but not for IL1 $\beta$ and IL6 and therefore non-parametric tests were used to study the single variables. To evaluate whether there were significant differences between levels of single variables in the different groups, Fisher's least significant differences procedure was used: first a Kruskal Wallis test was performed and next two groups at a time were compared using a Mann-Whitney test to determine which differences between groups were significant.

Because the fibrinogen levels were normally distributed after a logarithmic transformation, the effect of smoking on fibrinogen in CAD patients and healthy controls and the effect of coronary heart disease in non-smoking and smoking individuals were studied after adjusting the fibrinogen levels for CRP and IL6 in a multiple regression analysis.

\section{Results}

When the plasma levels of acute phase proteins in the patient group were compared with those in the control group, the fibrinogen levels in the patients appeared to be significantly higher than those in the healthy controls (Table 1). No differences for CRP were found. When comparing the plasma levels of the individual cytokines, only significantly higher IL6 levels were observed and not significantly higher ILl $\beta$ or TNF $\alpha$ levels.

The effect of coronary artery disease was then studied in the non-smokers and the smokers separately. In the non-smokers the difference in the plasma fibrinogen levels between the healthy vol- 
Table 1

Median (10-90 percentile range) of acute phase markers in healthy controls and patients

\begin{tabular}{llll}
\hline & Controls & Patients & $P$ \\
\hline Fibrinogen $(\mathrm{g} / \mathrm{l})$ & 2.09 & 2.87 & 0.0002 \\
& $(1.55-2.78)$ & $(1.94-4.19)$ & \\
C-reactive protein & 1.99 & 1.3 & 0.54 \\
$\quad(\mathrm{mg} / \mathrm{l})$ & $(0.33-9.15)$ & $(0.47-8.18)$ & \\
Interleukin-6 (pg/ml) & 3.0 & 3.0 & 0.02 \\
& $(3.0-3.0)$ & $(3.0-17.5)$ & \\
Interleukin-1 $\beta(\mathrm{pg} / \mathrm{ml})$ & 3.0 & 3.0 & 0.40 \\
& $(3.0-11.9)$ & $(3.0-7.3)$ & \\
Tumour necrosis & 8.8 & 8.7 & 0.96 \\
factor- $\alpha(\mathrm{pg} / \mathrm{ml})$ & $(3.9-24.5)$ & $(3.5-29.3)$ & \\
\end{tabular}

$P$ gives the significance between the control and patient group as found using the Mann-Whitney test.

unteers and the patient group was more pronounced than in the smokers $(+0.94 \mathrm{~g} / 1(49 \%$, $P=0.02)$ and $+0.57 \mathrm{~g} / 1(25 \%, P=0.008)$, respectively) (Table 2). The levels of CRP were low in non-smoking patients and controls and higher in smoking patients and controls. The effect of CAD on IL6 levels was significant in smokers only, and many had IL6 levels below the detection limit. In the Kruskal Wallis analysis no significant differences between groups were found for ILI $\beta$ and TNF $\alpha$.
When the fibrinogen levels were adjusted for CRP and IL6 to remove the acute phase component, the values were still significantly higher in non-smoking patients than in non-smoking controls $(P<0.001)$ and in smoking patients when compared with smoking controls $(P=0.03)$. This suggests that the effect of CAD on the plasma fibrinogen levels is regulated, as least partly, by a mechanism other than that which regulates the inflammatory markers CRP, IL6, IL1 $\beta$ and TNF $\alpha$.

The effect of smoking was then studied in the patients and in the control group. The fibrinogen levels were similar in non-smoking and smoking patients, whereas there was a trend for an increase of $0.36 \mathrm{~g} / 1$ in smokers $(19 \%, P=0.10)$ (Table 2, Fig. 1). Furthermore, it was observed that smoking gives a comparable increase of the CRP levels in CAD patients and in healthy controls $(+2.1$ $\mathrm{mg} / \mathrm{l}(254 \%)$ and $+3.0 \mathrm{mg} / \mathrm{l}(297 \%)$, respectively) (Table 2, Fig. 2). In many individuals in our study the levels of the IL6 and IL1 $\beta$ were below the detection limit of $3.0 \mathrm{pg} / \mathrm{ml}$ (Table 2, Fig. 3). Only in smoking CAD patients were the levels of IL6 significantly increased. No effects on the IL1 $\beta$ and TNF $\alpha$ levels were found.

When the fibrinogen levels were adjusted for CRP and IL6 smoking did not have an effect,

Table 2

Median (10-90 percentile range) of acute phase markers in healthy controls and patients, considering their smoking status

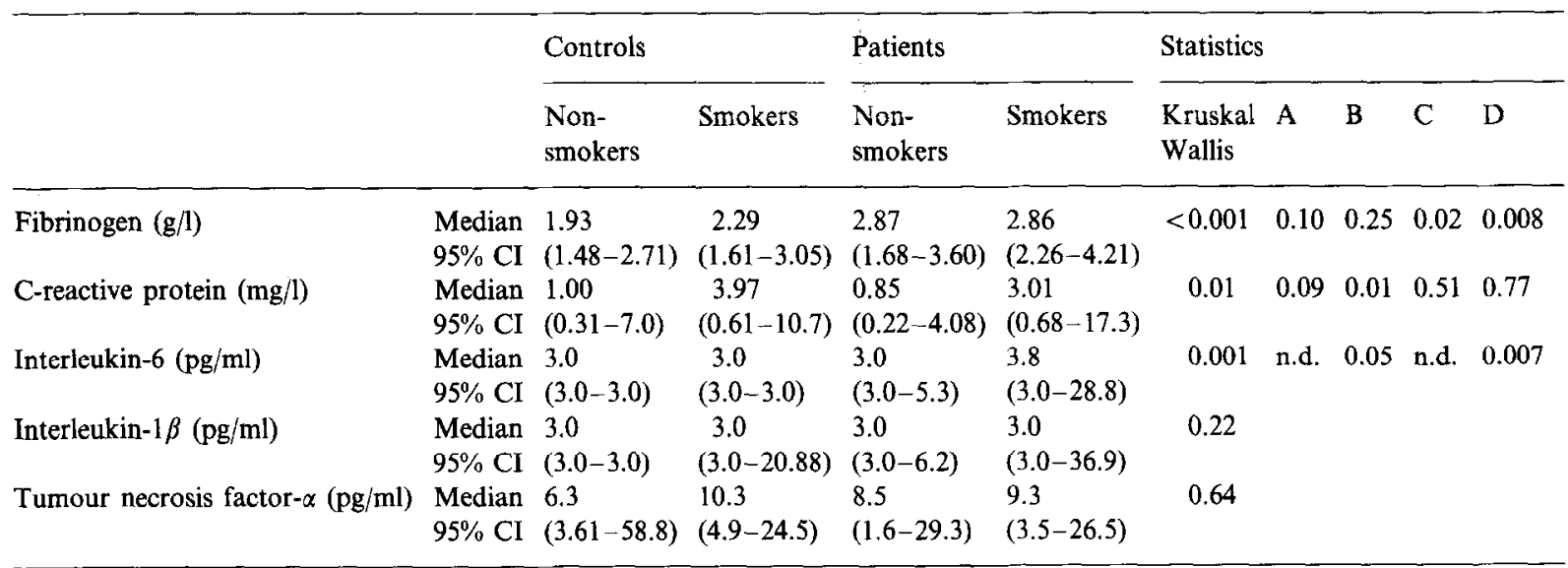

Significance levels in columns: A, between non-smoking and smoking controls; B, between non-smoking and smoking patients; C, between non-smoking controls and non-smoking patients; D, between smoking controls and smoking patients. n.d., not determined (too many very low levels). 


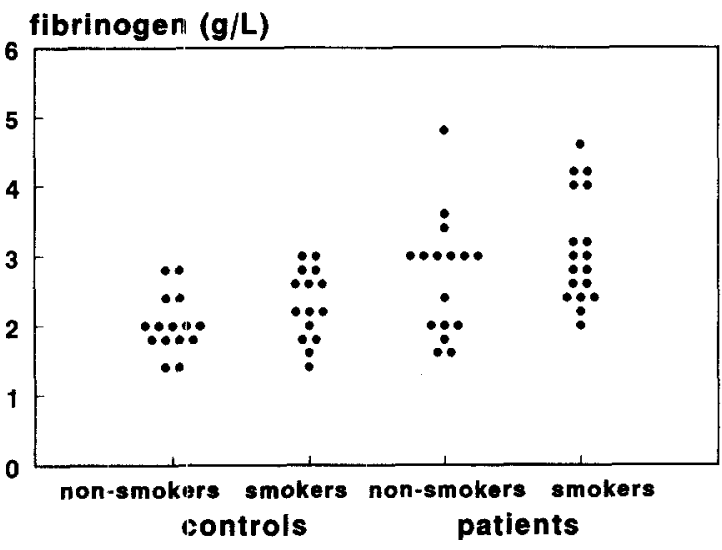

Fig. 1. Fibrinogen levels for non-smoking and smoking controls, and non-srnoking and smoking patients.

while the effect of CAD remained after adjusting (see above), suggesting that the inflammatory reaction induced by smoking affects the studied parameters in a similar way.

\section{Discussion}

The plasma level of tibrinogen is associated with the extent of atherosclerosis and is also related to the risk of CAD. Since it has been hypothesized that inflammation of the vascular wall underlies the increased fibrinogen levels, we studied the relation between plasma fibrinogen levels and a selection of inflammatory markers, namely CRP, IL6, IL1 $\beta$ and TNF $\alpha$, in patients

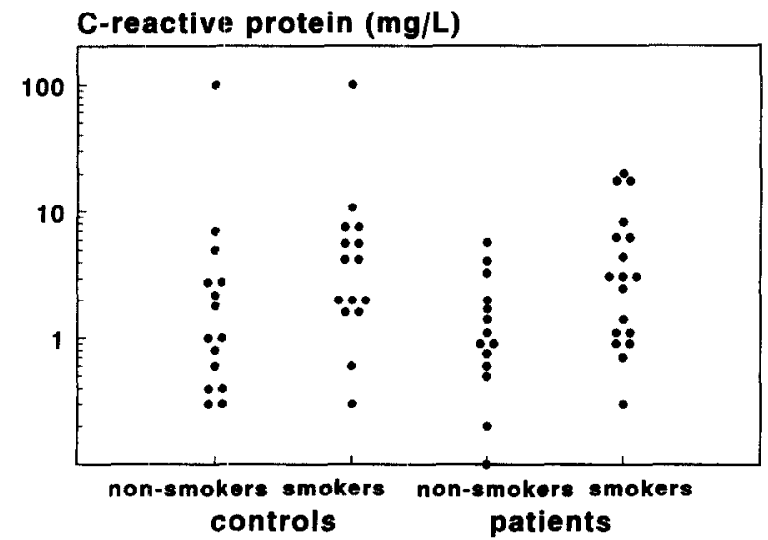

Fig. 2. C-reactive protein levels for non-smoking and smoking controls, and norl-smoking and smoking patients.

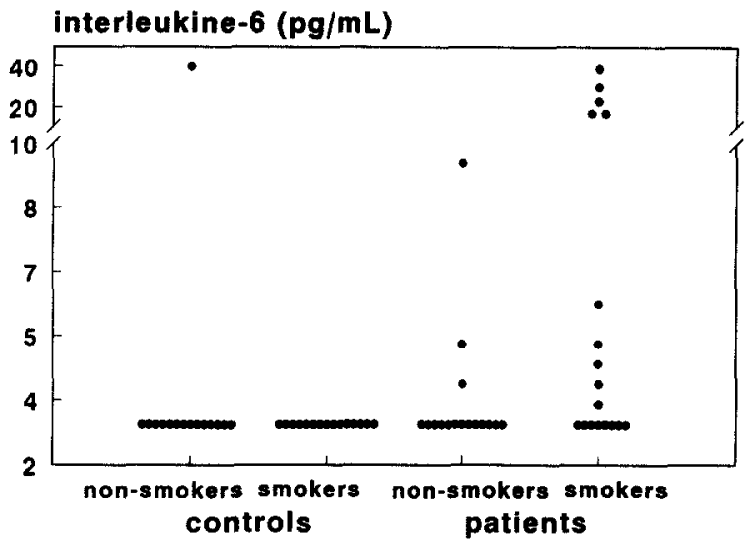

Fig. 3. Interleukin-6 levels for non-smoking and smoking controls, and non-smoking and smoking patients.

with severe CAD and in healthy volunteers. The patients had significantly higher levels of fibrinogen and IL6 than controls, in accordance with that hypothesis. However, the levels of the very sensitive acute phase protein CRP did not differ between patients and healthy volunteers.

Since it is known that the levels of the acute phase proteins are associated with smoking, the effect of CAD was analysed separately in nonsmokers and in smokers. We found that smoking did not increase the fibrinogen levels in our CAD patients further, but had a small effect in healthy volunteers. Apparently, CAD is a major determinant for increased fibrinogen levels. This finding agrees with the results of the PLAT Study [25] and the ECAT Angina Pectoris Study [26] describing a minor effect of smoking on the plasma fibrinogen levels of patients with vascular disease, and studies in healthy volunteers which reported a positive effect of smoking [3,15-18].

The behaviour of CRP was different from that of fibrinogen, since levels were equally elevated by smoking in the controls and the patients. Acute phase proteins, especially CRP, react strongly to inflammatory reactions. In this study, we show that smoking is a strong determinant of the plasma fibrinogen levels, while the effect of CAD is negligible.

The increase of the levels of the acute phase markers CRP and IL6 by smoking in controls and CAD patients supports the hypothesis of an increased inflammatory status in smokers. The syn- 
thesis of fibrinogen and CRP in the liver is mainly regulated by IL6, IL1 $\beta$ and TNF $\alpha$ [14]. However, in this study the levels of IL6 are higher in smoking than in non-smoking patients, but not in controls. Apparently, the inflammatory reaction caused by smoking is not sufficient to increase the levels of this cytokine.

In the ECAT Angina Pectoris Study both fibrinogen and CRP levels were risk indicators for cardiovascular events, but when the inflammatory component was removed from the plasma fibrinogen levels by adjusting them for CRP, fibrinogen was still an indicator for risk. This suggests that the level of fibrinogen is not merely an epiphenomenon of the inflammatory reaction. Therefore, we evaluated whether the acute phase reaction was the only regulatory mechanism that contributed to the observed increase in the levels of fibrinogen by adjusting the fibrinogen levels for CRP and IL6. The effect of smoking in controls was reduced, indicating that smoking indeed induces an inflammatory response. However, both in smokers and in non-smokers, a significant influence of atherosclerosis on the fibrinogen levels still remained. This implies that the inflammatory markers that we studied have a complex behaviour or that another mechanism may also be involved here, which may be at least partly genetic, as it has been reported that up to $51 \%$ of the fibrinogen level is genetically determined $[30,31]$.

In summary, we have shown that (1) in patients with CAD, levels of fibrinogen and IL6 are increased, and not CRP when compared with controls; (2) CAD has a greater effect on fibrinogen levels than smoking; (3) smoking, but not CAD, affects the levels of CRP; and (4) the effect of CAD on the level of IL6 depends on smoking. Therefore, the increase of the plasma fibrinogen levels in patients with CAD cannot be fully explained by an increased inflammatory status reflected by IL6 and CRP.

\section{Acknowledgements}

This study was subsidized in part by the Dutch Heart Foundation Grant 90.275. We thank Dr. T.
Stijnen for his statistical advice and the Rotterdam Red Cross Blood Bank for their cooperation in providing the control group.

\section{References}

[1] Ernst E. Plasma fibrinogen - an independent cardiovascular risk factor. J Intern Med 1990;227:365.

[2] Meade TW, Brozovic M, Haines AP, Imenson JD, Mellows S, Miller GJ, North MRS, Stirling Y, Thompson SG. Haemostatic function and ischaemic heart disease: principal results of the Northwick Park Heart Study. Lancet 1986;2:533.

[3] Thompson SG, Kienast J, Pyke SDM, Haverkate F, van de Loo JCW. Hemostatic factors and the risk of myocardial infarction or sudden death in patients with angina pectoris. N Engl J Med 1995;332:635.

[4] Naito M, Hayashi T, Kuzuya M, Funaki C, Asai K, Kuzuya F. Effects of fibrinogen and fibrin on the migration of vascular smooth muscle cells in vitro. Atherosclerosis 1990;83:9.

[5] Dejana E, Languino LR, Polentarutti N, Balconi G, Ryckewaert JJ, Larrieu MJ. Interaction between fibrinogen and cultured endothelial cells. J Clin Invest 1985;75:11.

[6] Leschke M, Blanke H, Styellwaag M, Motz W, Strauer BE. Hyperfibrinogenämie und pathologische Plasmaviskosität. Dtsch Med Wochensch 1988;113:1175.

[7] Ross R. The pathogenesis of atherosclerosis: a perspective for the 1990s. Nature 1993;3662:801.

[8] Kannel WB, Anderson K, Wilson PWF. White blood cell count and cardiovascular disease. Insights from the Framingham Study. J Am Med Assoc 1992;267:1253.

[9] Nieto FJ, Szklo M, Folsom AR, Rock R, Mercuri M. Leucocyte count correlates in middle-aged adults: the atherosclerosis risk in communities (ARIC) study. Am J Epidemiol 1992;136:525.

[10] Olivares R, Ducimetiere P, Claude JR. Monocyte count: a risk factor for coronary heart disease? Am J Epidemiol 1993; 137:49.

[11] Barath P, Fishbein MC, Cao J, Berenson J, Helfant RH, Forrester JS. Detection and localization of tumor necrosis factor in human atheroma. Am J Cardiol 1990;65:297.

[12] Mazzone A, De Servi S, Ricevuti G, Mazzucchelli I, Fossati G, Pasotti D, Bramucci E, Angoli L, Marsico F, Specchia G, Notario A. Increased expression of neutrophil and monocyte adhesion molecules in unstable coronary artery disease. Circulation 1993;88:359.

[13] Wal van der AC, Becker AE, Das PK. Medial thinning and atherosclerosis - evidence for involvement of a local inflammatory effect. Atherosclerosis 1993;103:55.

[14] Kusher I. Regulation of the acute phase response by cytokines. Perspect Biol Med 1993;36:611.

[15] Korsan-Bengtsen K, Wilhelmsen L, Tibblin G. Blood coagulation and fibrinolysis in a random sample of 788 
men 54 years old. II. Relations of the variables to 'risk factors' for myocardial infarction. Thromb Diath Haemorrh 1972;28:99.

[16] Ernst E. Fibrinogen, smoking and cardiovascular risk. J Smoking-Relat Dis 1993;4:37.

[17] Meade TW, Imeson J, Stirling Y. Effects of changes in smoking and other characteristics on clotting factors and the risk of ischaemic heart disease. Lancet 1987;1:986.

[18] Das I. Raised C-reactive protein levels in serum from smokers. Clin Chim Acta 1985;153:9.

[19] Allen RA, Kluft C, Brommer EJP. Effect of chronic smoking on fibrinolysis. Arteriosclerosis 1985;5:443.

[20] Holt PG. Imrnune and inflarnmatory function in cigarette smokers. Thorax 1987;42:241.

[21] Yarnell JWG, Sweetnam PM, Rogers S, Elwood PC, Bainton D, Baker IA, Eastham R, O'Brien JR, Etherington MD. Some long term effects of smoking on the haemostatic system: a report from the Caerphilly and Speedwell Collaborative Surveys. J Clin Pathol 1987;40:909.

[22] Kannel WB, D'Agostino RB, Belanger AJ. Fibrinogen, cigarette smoking, and risk of cardiovascular disease: insights from the Framingham Study. Am Heart J 1987;113:1006.

[23] Møller L, Kristensen TS. Plasma fibrinogen and ischemic heart disease risk factors. Arteriosclerosis Thromb 1991;11:344.

[24] Krobot K, Hense HW, Cremer P, Eberle E, Keil U. Determinants of plasma fibrinogen: relation to body weight, waist-to-hip ratio, smoking, alcohol, age, and sex. Arteriosclerosis Thromb 1992;12:780.
[25] Cortellaro M, Boschetti C, Cofrancesco E, Zanussi C, Catalano M, de Gaetano G, Gabrielli L, Lombardi B, Specchia G, Tavazzi L, Tremoli E, Della Volpe A, Polli E, PLAT Study Group. The PLAT Study: a multidisciplinary study of hemostatic function and conventional risk factors in vascular disease patients. Atherosclerosis 1991;90:109.

[26] ECAT Angina Pectoris Study: baseline associations of haemostatic factors with extent of coronary arteriosclerosis and other coronary risk factors in 3000 patients with angina pectoris undergoing coronary angiography. Eur Heart J 1993;14:8.

[27] Pietersma A, Kofflard M, de Wit LEA, Stijnen T, Koster JF, Serruys PW, Sluiter W. Late lumen loss after coronary angioplasty is associated with the activation status of circulating phagocytes before trcatment. Circulation 1995;91:1320.

[28] Caswell M, Pike LA, Bull BS, Stuart J. Effect of patient age on tests of the acute-phase response. Arch Pathol Lab Med 1993; 117:906.

[29] Hoegee-De Nobel E, Voskuilen M, Briët E, Brommer EJP, Nieuwenhuizen W. A monoclonal antibody-based quantitative enzyme immunoassay for the determination of plasma fibrinogen concentrations. Thromb Haemostas $1988 ; 60: 415$.

[30] Hamsten A, Iseluis L, de Faire U, Blomback M. Genetic and cultural inheritance of plasma fibrinogen concentration. Lancet $1987 ; 2 ; 988$.

[31] Humphries SE, Cook M, Dubowitz M, Stirling Y, Meade TW. Role of genetic variation at the fibrinogen locus in determination of plasma fibrinogen concentrations. Lancet 1987;1:1452. 